short-term contracts (not subject to the control of the Medical Practices Committee) for vocationally trained GPs entering inner city practices.

I recently sent this list to the Chief Medical Officer, in order to discover which of these we might implement locally, but was disappointed to be told that the answer was none, because "the FPC does not have the sort of discrimination you have in mind to alter locally the GPs' detailed terms of service or the scheme of fees and allowances under which the practitioner is paid. It is a question of settling arrangements nationally which are flexible enough to enable them to be adapted to provide local solutions in all circumstances." The General Medical Services Committee and DHSS report on under-doctored areas ${ }^{3}$ would appear to offer little hope for any change in this situation.

The 1974 reorganisation of the NHS was intended to integrate primary and secondary care and to achieve minimum national standards via the new systems for planning and resource allocation. If the Government really puts patients first then surely it is time to grant health authorities the opportunity for positive discrimination in the development of general practice in inner cities, and to integrate the planning and resource allocation systems, so that central priorities have a real chance of becoming local realities.

Alex Scott-Samuel

Liverpool Area Health Authority

Liverpool L3 9NG

${ }^{1}$ Mersey Regional Health Authority. Report of a committee of inquiry. January 1978.

(19.8

Anonymous. Br Med 7 1979;ii:1380-3.

SIR,-In his letter (9 February, p 407) Dr J A Jewell refers to the idea of an initial practice allowance for inner city areas. As he says, this has been proposed by the Working Party on Under-doctored Areas. Before this suggestion becomes accepted uncritically as "a good thing" we should examine it more closely.

The "legendary aging singlehanded practitioners" to whom Dr Jewell refers have smal lists of patients. The income from their practices may be adequate for elderly doctors with few expenses. For a young man with a family who has to live in London a list of 1000 or 1200 patients is simply not large enough. To augment his income for a few years by a special allowance assumes that he will eventually increase his list to, say, 2500; but this can be done only at the expense of neighbouring practices.

The population of inner London has been falling steadily for the past 30 years. Many general practitioners have kept going only because the Executive Council and the family practitioner committees have dispersed these small lists or transferred the patients to adjacent practices. This policy could be changed, of course, but such a change would have to take heed of the interests of the doctors who are giving general medical services at present. The situation is quite different from that in the New Towns, where at first there are no doctors and a growing population. To introduce a salaried service on a piecemeal basis side by side with independent contractors would lead, in a few years, to everyone trying to survive with small and dwindling lists.

\section{Closing the gap between GPs and} hospitals

SIR,-While I agree that the profession should maintain as close a working relationship as possible between the GP and his hospitalbased colleagues, Dr J Crane's proposals to close the gap (9 February, p 423) are based on false assumptions about the nature of the general practitioner's role.

A GP is, by definition, a generalist and an individual. Primary care medicine in this country functions on this assumption and eliminates the need for a patient to make a self-diagnosis, a prerequisite where there is direct access to a specialist. Furthermore, most patients prefer to relate to an individual doctor rather than a "group." The specialist has evolved as a feasible solution to the ever-continuing explosive advancement of medical knowledge. It is assumed that it is better for a practitioner to deal knowledgeably with a few diseases than inadequately with all diseases. There can be no argument about this if we are considering the understanding of specific diseases.

Primary care medicine deals with the breakdown of health in all its aspects. Specific diseases are only one aspect of this. Indeed, it is the preoccupation with specific diseases (an inevitable consequence of medical education based largely on hospital experience) which often leads to difficulties in effecting good general practice, something which needs to concern itself as much with the philosophical aspects of ill health as it does with compartmentalising individual illnesses. To say that clinical observation is only a preliminary to choosing an appropriate diagnostic technique is to be blinded by technology and obsessed by a need to make definitive diagnoses. The prime concern for the GP should be in helping the patient to achieve overall improvement in health, restricting diagnostic techniques and specialist involvement merely as a means to this end. In most instances the GP is able to base his conclusions on observation alone.

It has also been observation of illness in the community rather than advances in "high technology" which has increased understanding of the genesis of ill health and its relation to the style of living of the patient and his family. To assume, as Dr Crane has done, that "the rapidly changing face of twentieth century medicine" is a phenomenon confined solely to hospital experience is to imply that practice of medicine in the community cannot advance itself without direct reference to hospital-based medicine. Ideally, the two should run in parallel, both maintaining their own degree of excellence. Each should understand what the other is trying to achieve without losing sight of their individual roles. If the specialist moves too near the community and the GP becomes too preoccupied with inpatient care and specialisation there is a real danger that neither group will achieve its full potential.

Bath BA2 4BY

R L RoLLS

\section{A4 records}

SIR,-Dr F J Borchardt (9 February, p 407) draws attention to the growing requirement for A4 records. In 1976 the annual conference of local medical committees approved a motion from the Berkshire Local Medical Committee "that this conference accepts that the A4 type of record folder is an improved method of record keeping with significant benefits in patient care." However, the 1975 conference was adamant that before any general introduction of this system the Department of Health and Social Security would have to give a firm undertaking that any consequent alterations to equipment and premises arising therefrom would be financed by the Department. The latter issue has not yet been resolved and the Department has been extremely reluctant to supply A4 records.

The GMSC recently agreed that the Department should now be urged to provide these records for doctors who request them in practices where suitable accommodation already exists, and the Royal Commission on the National Health Service recommended that they should be introduced as a matter of priority. Because of this complicated situation many doctors are reluctant to part with their A4 folders and certainly they should not be sent to colleagues who are unwilling to use them. I feel therefore that the best way to progress is by pressure on the Department at a national and individual practice level for a liberal supply of these records.

The interesting suggestion for amending the FP4 to include an "A4 acceptable box" may not be well received as it would entail an alteration to a national medical card and might only be necessary for a period of a few years until the problems are resolved. It might, however, be worth individual colleagues themselves entering prominently "A4 acceptable" on the FP4s to see if this evokes any response through the family practitioner committees.

It is an appropriate time to move forward on this issue as doctors who use the A4 system, either in part or in whole, find it of considerable benefit, and trainees-who often have the unenviable task of searching through the standard record envelopes for informationare strongly in favour of them.

Reading, Berks RG3 3AN

GORDON TAYLOR

\section{Medical students and the HJSC}

SIR,-We are writing from the annual general meeting of the Medic's Working Party of the National Union of Students to register our disquiet over the proposed mechanism for election of two medical students to represent student views on the Hospital Junior Staff Committee (HJSC).

The Medics' Working Party is part of the Health Students' Section of the NUS, which represents all health students. The working party represents medics within the union, and is elected from our AGM. Although not all medical schools are members of the NUS they can all be involved in the Medic's Working Party and have full voting rights.

In the $B M \mathcal{F}$ (20 October, $p$ 1014) it was stated that an election was to be held for two student representatives to sit on the HJSC, and that only associate members of the BMA would be able to vote. We believe that this is totally undemocratic; only a proportion of medical students would be able to vote, and thus the students could hardly be representative of medics as a whole. The situation is particularly ludicrous since the HJSC is meant to be an "independent" committee and doctors involved in it do not have to be BMA members. 